\title{
CONTENTS
}

1 The Meaning of Meaning 1

2 Magical Rhetoric 26

3 Ontological Rhetoric 49

4 Objectivist Rhetoric 76

5 Expressivist Rhetoric 103

6 Sociological Rhetoric 130

7 Deconstructive Rhetoric 163

Afterword: Critical Reflections 193

References 201

About the Author 204

Index 205 


\section{THE MEANING OF MEANING}

What we believe about words influences the ways in which we live our lives, what we think and say and do. Notice that I'm not referring to our uses of language: it's obvious that speaking, writing, listening, and reading have consequences for our lives. What I'm suggesting is rather less apparent: attitudes we have, assumptions we make, beliefs we hold, mostly tacit and unexamined, about what language can do for us, how language works, its connections to the world, the reliability of meaning, the truth-value of different kinds of statements, all affect our lives just as much as, and perhaps even more deeply than, our actual usage. Anthropologist and linguist Edward Sapir, known for his insights into the relativity of representation across languages, argued the error of supposing that "one adjusts to reality without the use of language" and insisted that the "real" world is "to a large extent unconsciously built up on the language habits" of different groups of people. No two languages, he writes, "are ever sufficiently similar to be considered as representing the same social reality" (Sapir 1964, 69). Sapir's observations in linguistics (the study of language) are pertinent also for rhetoric (the study of discourse). That is, what he argued regarding different assumptions about words and reality in different languages anticipates similar distinctions among the multiple, complexly interwoven discourses, or communication practices, that compose social experience in any one language-domestic discourses (the verbal routines of everyday life), religious discourses, scientific, legal, political, medical, artistic, educational, scholarly, and other discourses. These discourses are themselves different worlds of words, albeit within a single language, and they feature, some more self-consciously than others, not just distinct vocabularies, syntactic styles, and registers, but different views of what C. K. Ogden and I. A. Richards (1923) called "the meaning of meaning"- -how things are named, what (if anything) is to be regarded as reliably "true," what counts as "proof," how the literal is distinguished from the figurative, who can speak authoritatively, what knowledge is and how it's achieved, 
and myriad other questions. In the most self-conscious of these discourses-religious, legal, or scholarly, for example-one commonly finds competing rhetorical theories vying for authority, with significant consequences attending the ebb and flow of alternative points of view. Ask a Catholic and an Anglican theologian about their contrasting views of the doctrine of transubstantiation, or two lawyers about the "intent" of the framers of the US Constitution, or two literary critics about their readings of "Young Goodman Brown," and conflicts regarding not just meaning but also the meaning of meaning will be quickly apparent.

\section{MEANING AND EVERYDAY LIFE}

But let's begin more simply with the familiar discourses of everyday life and consider the tacit rhetorical assumptions of a couple of ordinary Americans whom I will call, for ease of reference, George and Louise. Friday morning, George comes down to breakfast and the newspaper, observes while pouring milk on his cornflakes that the carton says "sell by September 15," which was two days ago, and, fearing the milk may be spoiling, plays safe and empties the carton in the sink. He reads a front-page story on a bond proposal to fund new buildings in his local school district and accepts the objectivity of the report along with the display of evidence supporting the need for new taxes to pay for the borrowing. He's unhappy, however, about Hispanic "aliens" driving up enrollment, and also with school programs that seem to put "multiculturalism" ahead of learning English. Turning to the editorial page, he finds a piece on global warming to be mere opinion, unsubstantiated by facts, its author melodramatic, and decides to withhold judgment until dispassionate science quiets the noise of discordant voices. As for the ad on page 6 hawking "eye-catching cosmetics," he recognizes the manipulative play of words, smirks briefly at the ad's fictions of beauty and sexuality, which he knows were conjured for commercial advantage, and dismisses its claims.

Reaching his office building later in the morning, he glances at the sign in the elevator warning not to exceed a limit of twelve occupants, takes it as an engineer's appraisal, casually estimates the number of his fellow travelers, and rides confidently to his workplace. He spends part of his work time writing proposals to potential business customers that detail how his consulting firm can troubleshoot their management practices and present software solutions. He is confident that his statements are accurate, unbiased, clear, and true, as professional writing is supposed to be, and he trusts that the precision of the language will allow 
the document to have contractual force if his firm's bid is accepted. Arriving home that afternoon, he sorts his mail, saving a notice of jury duty in two weeks and throwing away a breathless proclamation that he has won a Caribbean cruise, not bothering to open the official-looking envelope. He listens to a phone message from his mother but dismisses her familiar complaint that he "never calls" as an unreasonable plea for attention. In the evening, he watches the televised hearing on a Supreme Court nominee, marking the candidate's views on the first and second amendments. Before bedtime, he amuses himself with a history of the Crimean war; he rarely reads novels and doesn't like poetry. First thing Saturday morning, George, a devout Catholic, goes to confession at his church, admits to the priest that he has failed recently to "keep holy the Sabbath day," and earnestly recites the requisite Hail, Marys and Our Fathers as penance, confident that he has been forgiven. On the way home, he notices a traffic sign saying "No U Turn." He makes a U turn anyway to park in front of his house, interpreting the meaning of the sign as "don't turn unless you're sure there is no oncoming traffic."

Louise follows similar routines, motivated (in part) by equally tacit, occasionally different, assumptions about language. She reads the sale date on the milk carton as an approximation only and decides to keep her milk, sees the bond issue article as an argument motivated by the political slant of the newspaper, and approves the global warming editorial, impressed by the urgency of the writer's prose. She glances at a letter to the editor in which the writer refers to Palestinian militants as "freedom fighters," a label with which she disagrees strenuously, believing that the militants are just plain terrorists. Like George, she sees a cautionary notice in her workplace elevator but regards it not as an example of engineering discourse but as a legal statement protecting the manufacturer from liability if the elevator fails when too fully loaded. She is skeptical about the safety of elevators and often climbs the stairs to her office. She spends part of her workday writing an online human resources newsletter that relies on a friendly, personal touch to maintain a positive image of her company while giving employees valuable information in user-friendly language supported by clever graphics and humorous anecdotes. She has always been grateful to her ninth-grade English teacher for giving her the grammatical proficiency that has made her so successful in her job. Even her diary entries are carefully crafted. After work, she sorts her mail, planning to query an official notice that her electric bill payment is late, worrying about how her mother's letter complaining of loneliness illustrates her failures as a daughter, and opening the same notice George received 
about a Caribbean cruise package, just in case. Her brother emails that evening, promising to come soon for a visit. She responds with the requisite expressions of eager anticipation, but she knows that he rarely follows through and she isn't particularly interested in seeing him anyway. Saturday morning, she heads for the beach, following directions on her GPS. A sign prohibiting $U$ turns obliges her to go around the block to reach the freeway, which she willingly does because the law is the law.

There may be little, if any, articulate awareness of language directly motivating what George and Louise say, understand, or do. Like the rest of us amidst our ordinary routines, they probably find just thinking to be challenging enough without also consciously thinking about their thinking. Yet they are immersed in language, and their thoughts as well as actions are influenced by a rich array of beliefs and assumptions about words. The beliefs come from lifelong interactions with other people (whoever pointed to a mooing creature and called it a cow "explained" to them that language can name things), from their schooling, including Louise's helpful ninth-grade teacher, and from their practical experience of the world, an experience that has been preshaped, to a greater extent than they probably realize, by their cultural background, language included. What they believe comes to them as settled understanding rather than theory or argument, mostly from the European inheritance of linguistic and rhetorical speculation that has served for centuries as the repository of our cultural common sense about language and discourse. It would take many pages to explain the details and nuances of this common sense, even limited to the thoughts and actions described above, but a sampling of its axioms should be sufficient to make the point. The most important belief George and Louise share is that language enables people to name, experience, organize, manage, and interact with realities that are different from and "outside" of language, including a world beyond the self (other people, human institutions, nature) and also a world within the self (feelings, ideas, memories, fears, hopes, imaginings). They presume that language represents these worlds and enables us to function within them. The warning on the milk carton doesn't cause milk to spoil. Rather, milk spoils, and the warning predicts approximately when it will happen. Louise's GPS directions to the beach don't create the road system; they only offer a symbolic rendering and convenient instruction about the best roads to take. For George and Louise, things precede the names we give them: real money underlies taxes and bond proposals; physical heat gives meaning to words like warming and cooling; actual cosmetics come before the ads that promote them. It follows, then, that the truth and accuracy of language involve a correspondence 
between words and the worlds to which words refer. George's professional writing names problems that really exist in a potential client's business operations, and it offers solutions whose validity and practicality can be objectively demonstrated. Louise's representations of her company, and her HR advice to employees, may be judged as true or false by matching them to employees' actual experience. Louise's electric bill is inaccurate because she has paid it. Substance is always more important than form. George and Louise don't use the word rhetoric very often, but when they do, it's a disparaging reference to language without substance, such as the advertising language George scorns as he reads the cosmetics ad. Louise exploits the clever graphics in her desktop publishing program, but she believes that her PR language is substantial, not mere rhetoric, because it offers real information; it is user-friendly but not misleading or manipulative.

George and Louise also believe in common that language enables communication. They communicate with family, friends, business associates, public institutions, service providers, even supernatural beings in George's case, generally confident that what they say is understood. People also communicate with them through talk and through a variety of media, including television, Facebook, e-mail, text messages, blogs, books, newspapers, telephones, letters, business memos, and official documents. They are satisfied that the interchanges, the sending and the receiving, create and maintain valuable, or at least useful, human relationships. George's business writing not only speaks the truth by naming problems and solutions, but it also communicates that truth to a potential client and makes a promise that his company will perform effectively in accordance with the statements in the proposal. The writing must be clear and technically correct, however, in order to be reliable. Clarity and correctness assure translucent communication, resulting in social bonds that enable the mutually beneficial conduct of commerce and daily life. Of course, because of the prior belief that words are subordinate to things, both George and Louise understand that actions speak louder than words. George's business contract is a promise, but it doesn't in itself get the work done. Louise believes that she and her brother know and relate to each other partly as a result of their ability to communicate, but she also knows that what her brother says in his e-mail message must be contextualized by earlier failures to follow through with actual visits. More generally, what people say must always be evaluated by reference to what is "actually" the case. That's how we tell the difference between truth, error, and deceit, not to mention the subtler difference between deceit and that socially strategic but ethically complex misrepresentation 
that enables Louise and her brother to maintain a sibling relationship despite the fact that he doesn't really travel to see her and she doesn't really care. Most of the time, words need to be interpreted, not just taken at face value, depending on how much we know about the speaker's intentions and about the communicative context. George and Louise draw different conclusions from the message in the elevator and partly (but only partly) base their actions on what they read. George believes that his mother's complaint about his never calling fails to match the reality of his frequent-enough calls, so he comfortably interprets her statement either as erroneous (in her case, forgetful) or as communicating something different from what it actually says, namely that his mother is lonely. Both George and Louise believe that we cannot only match language to factuality but that we can look through a verbal statement to perceive the intent of the person who makes it. They both "know" what their mothers mean, and what the elevator signs mean, and they confidently, though differently, appraise the truth-value of each.

For Louise and George, different statements have different truth-value, and they trust them more or less depending on the ways in which they are classified and ranked. George's hierarchy of statements begins with the Word of God. He believes that there are sacred utterances, like the Bible, that speak to human beings with divine authority and also that there are specialized human utterances that have the power to affect supernatural or divine agencies, including prayers and rites such as Catholic confession. George finds the authority of the newspaper's front-page stories more compelling than the editorials and the editorials more persuasive than the advertisements. The letter announcing his entitlement to a Caribbean cruise is at the bottom of the hierarchy, not just manipulative but deceitful. His mother's message is more reliable than the cruise letter because it doesn't lie but less reliable than the newspaper because his mother's message is more influenced by personal bias. He finds, as most people in our culture probably do, that there is more truth-value in "realistic" writing, like history, than in fiction writing, that prose is more reliable than poetry, and that argument is more reliable than narrative. Louise's hierarchy makes room for the value and usefulness of personal, not just "objective," writing because the sincerity of personal writing assures the reliability of its statements. She believes that writing can portray the self and connect with the inner beings, the selves, of others. Whether she is writing in her diary, communicating with her mother, or informing her colleagues at work, she has confidence that sincerity is a basis for authenticity, that statements "from the heart" have more value than rhetorical manipulations of seeming objectivity. Louise recognizes that the apparent detachment 
of front-page articles may conceal a newspaper's political and mercantile agendas, just as the caution sign in the elevator can be more protective of the manufacturer than the riding public, so she interprets both with more skepticism, less trust, than George does. The passionate conviction of the global-warming argument gives its author integrity: she knows where the writer stands. Of course, Louise isn't invariably skeptical about objective narrators. For example, she does not read ulterior motives into the sign prohibiting $\mathrm{U}$ turns, accepting the authority of this particular civil discourse without presuming to retain any interpretive license. George, by contrast, regards a commandment to keep the Sabbath as different from a commandment to avoid U turns, although the differential regard is more likely a consequence of rationalized self-interest than a parsing of the degrees of authority implicit in religious and civil discourses. Beliefs about language, whether Louise's or George's or our own, do not have to be philosophically consistent with each other, or consistently applied, and they are always modified by other complexities of human motive and behavior.

Still more beliefs and value-laden assumptions can be mined from this brief encounter with George and Louise. Both of them agree that the primary value of literacy, the ability to read and write, is mainly practical, allowing the deployment of language skills for social and economic advantage. George clearly believes, with many Americans, that "foreigners" should speak our language if they are going to live in our country. Louise believes that language is comprised of building blocks (syllables, words, sentences, paragraphs) that are joined together to form ever-more-elaborate statements, and that teaching reading and writing requires learning to manipulate the building blocks from simplest to most complex. She thanks her ninth-grade teacher for these insights. It is likely that both George and Louise believe that fundamental realities are the same around the world regardless of language and other cultural differences, that talk is cheap, that really important public documents—contracts, laws, medical records-are reliable, and that immoral writing can corrupt the young and/or ignorant. One could go on, but my concern is only to underscore the observation with which I began: what we believe about words influences the ways in which we live our lives. Every statement identified by italics in the preceding paragraphs constitutes an axiom from the cultural common sense of the West regarding language and discourse. It belongs to a dispersion of beliefs, values, assumptions, ideas, opinions, practical lore, superstitions, and fragments of formal theory accrued over many centuries, generally below the radar of conscious attention, working in concert (and even in contradiction), to reassure George, Louise, and the rest of us that we can all rely on speech acts. The 
statements, taken together, comprise a "story" about language and discourse, or rather a collection of stories, an "anthology," whose overlapping themes and narratives preserve a multifaceted picture of communication in our cultural memory. While the stories portraying these beliefs include analytical arguments from linguistics and rhetoric, they are not invariably scientific, consistently theoretical, internally consistent, logical, or even fully articulate. They come from the West's mythico-religious traditions as well as from philosophy, and from experiential lore as well as disciplined knowledge. Their treatment of shared themes varies dramatically from one to another without the demands of proof or consistency expected from scientific or other argumentative discourse. No one story in the anthology has the standing to refute another; their rival accounts simply offer a plurality of understandings. That's why the idea of story more effectively conveys the nature of our common sense about verbal communication than the idea of theory or argument.

The stories function in much the same ways as those in other areas of our cultural knowledge, such as our understanding of what it means to be American, of what comprises the American Dream. We can recall, with varying degrees of self-consciousness, stories about immigration, from the Mayflower to Ellis Island, about revolt against European tyranny, about hard-won political and religious freedoms, about Westward expansion, about the Blue and the Gray, about keeping the world safe for democracy, about progressing from rags to riches through selfreliance, pragmatism, and industry. Taken together, the stories identify and claim to validate "our" shared cultural heritage while also, in their diversity, evoking the complexities, discordances, and irreconcilable differences that make up the American experience. Different individuals and groups emphasize different stories, judging some true and others false, or some meaningful and others not. Not everyone agrees that all the stories are indeed common sense, as, for instance, those that relate mistreatment of Native and African Americans, or those that question whether America is truly a land of opportunity, or those that describe a separation of church and state. As an anthology, the stories reveal not a seamless unity of understanding but a compendium of viewpoints represented in differing treatments of recurring themes. They serve to legitimate those viewpoints, not only providing intellectual and emotional coherence to particular ways of seeing the world but also providing their tellers and listeners with political leverage in the ongoing negotiation of that group's standing or privilege. In general, stories shape the vagaries of actual experience in all areas of cultural life into ideological wholes, confirming fictions that offer historical context, personal and group 
identification, shared assumptions and values, and rationales for, as well as confidence in, the reasonableness of actions judged to be consistent with their perspectives. The cultural common sense they narrate is pervasive, self-evident, pragmatically effective, immune to falsification, and psychologically necessary for maintaining familiar pictures of the world and routines of human interaction.

Common sense is also, of course, to paraphrase Albert Einstein, the historical record of our prejudices. It is grounded in our oldest, or simplest, or most concrete, or most familiar, or most self-centered experiences (like "the sun rises in the east"), and because it is so serviceable, we generally accept it as authoritative. Yet it is also, in its familiarity, uncritical, and in its faithfulness to local perspective not only limited by that perspective but also unable to sympathize with alternative points of view, finding them wrong, ignorant, or meaningless. Returning to the issue of common sense about language and discourse, Louise's and George's beliefs reveal the influence of narrow perspectives whether they disagree with each other, for example, about the efficacy of religious discourse or share the same views while lacking awareness of vantage points available from other stories in the anthology. Consider the most important axiom they accept in common: the assertion that language names a preexisting world. This belief is neither timeless, nor self-evidently true, nor reliably confirmed by experience, nor unopposed by plausible (if not always intuitively sensible) alternative arguments. The story that relates it has a formal philosophical history, but while it enjoys considerable prestige in the repertory of narratives inscribing our common sense, it does not exhaust Western insight into the relationship between language and reality. To name just one alternative story (shortly, I will introduce more), some philosophers have argued that our sensory experience is already a human interpretation of the physical exteriority surrounding us, that even initial perception, let alone the processes of conceptualization and naming, serves to constitute (instead of mirroring or reflecting) the "reality" it presents to us. Words don't point to the world in this view; rather, they make it for us, presenting a "reality" that is comprehensible as reality because it is rendered in human terms. This is a transcendental, or romantic, story about meaning, while the more popular story is classical and metaphysical. For many people, and probably for George and Louise, the transcendentalist narrative is less intuitively familiar than the much older account of an intrinsically coherent world that the eye "sees" and language points to. But as later chapters will reveal, it has had a concrete, historical impact on the thinking, speaking, and acting of people who have lived according to the truth of its statements. 


\section{RHETORICAL PERSPECTIVES: NAMING}

I've argued so far that what we believe about language influences how we live our lives. Now I'd like to add that conscious thought about language, whether in the domestic discourses of everyday life or in more theorized professional discourses, can be beneficial for those who make the effort. Close reading and formal thinking about the stories that articulate our common sense can allow us to cultivate a curious, reflective, and critically distanced attitude toward the entire anthology as opposed to merely believing or disbelieving individual stories according to the accidental preferences of our experience, upbringing, or education. It means developing a similar attitude toward storytelling itself, appreciating its power to beguile no less than inform anyone who remains uncritical of its crafted illusions of certitude, coherence, and sufficiency. While one cannot live apart from stories, or achieve a transcendent location outside all narrative perspectives, reflective readers can retain the capacity to evaluate the claims of different stories, read new stories as though they too might have the potential to be true, and change their preferences in response to new ideas and experience. The axioms of common sense we've encountered so far belong to plausible European accounts of the nature of discourse that are neither ignorant, nor naïve, nor false-stories that have respectable intellectual pedigrees dating to Greco-Roman times and earlier. But the stories are also different. What I want to suggest is the value of approaching the stories comparatively and critically by reading them, along with others that are less familiar but not less influential, within the various philosophical, rhetorical, and linguistic traditions to which they belong. To do this kind of reading is to achieve perspective on language use, to reflect on the meaning of meaning, and to think about how people act when they participate in discourse. Reading different accounts of the nature and value of discourse doesn't in itself make us better language users, any more than studying ethics makes us better people. But it can enlarge our knowledge of discursive ideologies-those political no less than intellectual commitments that motivate people, including ourselves, to use language in particular ways, react differently to the language uses of others, and draw different conclusions about the authority, value, or significance of language acts. On occasion, this thinking about the meaning of meaning can have not merely intellectual but also practical value for recognizing and modifying ideological convictions-changing our minds about what we think and say and do.

Let's explore this last point in more detail because the knowledge available from conscious reflection on stories about the meaning of 
meaning is not as academic and esoteric as it might appear. It's true that everyday life, the world of George and Louise, is normally a low-stakes environment for rhetorical reflectiveness: the casual embrace of our personal discursive prejudices is adequate for getting through the day. But language plays many important roles in our lives, and sometimes the stakes are higher than merely the best interpretation of the sale date on a milk carton. Consider the basic, and usually straightforward, act of naming as a case in point. Naming-or representation-is one of the most familiar and important acts that language enables us to perform, and it is usually routine since most names enjoy broad social agreement. Sometimes, however, names are contested, and when they are, the reason is often more than academic: the disagreements can affect people's lives. Louise, for example, disagrees with the letter to the editor that names Palestinian militants as freedom fighters because she is convinced that the militants are terrorists. George refers to the rising Hispanic population as aliens rather than immigrants. Examples of high-stakes naming abound in the world of everyday life: Is someone who reports criminal conduct a police informant or a snitch? Is a social program favoring minority groups affirmative action or reverse discrimination? Is abortion about the right to life or the right to choose? Is evolution about natural selection or intelligent design? Does the practice of allowing people to choose their preferred elementary school constitute neighborhood bonding or segregation? Was the European conquest of the American Indian genocide or "manifest destiny"? Did the admissions policy of the medical school at UC Davis constitute an equal opportunity program or an unfair quota system-as the Supreme Court named it in the lengthy text of its 1978 decision in Bakke v. University of California? (Names can be texts of any size, not just nouns or noun phrases.) What is clear in each of these instances is that contested naming is not a trivial debate. How someone or something is named determines what the person or the thing $i s$, and participants in the debate understand that the outcome has public consequences for how people are going to be treated, how people will act, and how the world is going to be understood.

Contested names, like terrorist versus freedom fighter, bring into sharp relief questions at the heart of any story about discourse. What exactly does a name name? And what is the basis for a name's authority? Any such story includes a theme concerning reference, sometimes proposing, as we have already seen, that words point to worlds outside of language, sometimes contending that words constitute worlds inside the mind, or inside language itself, and sometimes offering mediations of these alternatives. The subtleties of reference are merely intellectual 
when the name rutabaga appears on a grocery list. But names like literacy or freedom or globalization or ethnic cleansing transport the intellectual issue into arenas of social, political, and other debate where the assumptions behind naming significantly shape the nature of public discussion. Let's grant Louise her contention that the Palestinians are terrorists, not freedom fighters (since for present purposes her choice is not pertinent to the discussion). What Louise believes about naming does not determine her view of the militants-that view depends on what she believes about geopolitics, or about violence, or about Arabs. But it affects the way she understands the worth or validity of her opinion, the way she responds to alternative points of view, the willingness she may have to reconsider her position, and the strategies she may use to persuade others that her view is correct. Her belief may even affect the authority she enjoys as a namer since that authority depends in part on the social legitimacy of her belief, the number of other people who understand the reliability of verbal statement in the same way she does. Louise is in competition with other namers, and she can't escape the obvious fact that some people see the Palestinians as freedom fighters. How she (or anyone) responds to the dissonance of contested names depends on her assumptions, whether tacit or examined, about what names name and how reliably they do it. Her assumptions constitute a discursive ideology where beliefs about language support, and are supported by, the power arrangements of public discussion.

Were Louise to consult the "anthology" of Western rhetoric, she would discover a surprisingly rich variety of theoretical responses to the question, what do names name? Here is an inventory of abbreviated alternatives, each of which I will introduce more formally, in its particular narrative context, later. One response is implicit in the biblical story of God speaking the world into existence ("God said, 'Let there be light"') and then authorizing Adam to name its natural variety. Naming is viewed here as a magical or sacred act, where a supernatural agency composes the "presence" of reality in words. If Louise accepts this view, then the letter writer in the newspaper is incorrect in naming the militants freedom fighters because, in effect, God has provided us with the ability to recognize them as terrorists: the thing is immanent in the name. A second response is that naming is an ontological act, where metaphysical constants (Being) that underlie the world's experiential complexity (Becoming) make it possible to define names with philosophical reliability as they refer to things beyond language. If Louise accepts that view, then the writer is incorrect because we know the definition of terrorist and can determine with metaphysical confidence that 
militant Palestinians fit the definition. Both magical and ontological theories argue that names name a reality beyond themselves, but they differ in supposing either a sacred or a rational basis for the connection. A third response is that naming entails empirical analysis, where the gradual accretion of evidence reveals with increasing precision the appropriateness of a particular representation. Names in this account denote concepts-mental constructs-derived from ranges of experiential information, not fixed realities that exist prior to conceptualization. Through observation and testing, references are established that correspond "objectively" to external experience. If Louise believes this view, then, in principle, the Palestinians may or may not be terrorists, and what we must do to determine the editorial writer's objective truthfulness is gather proof of the viability of the name he prefers.

A fourth response is that naming is an imaginative act in which human needs and predispositions invest experience with meaning. If Louise believes that view, she is obliged to concede that the writer is entitled to name the Palestinians as freedom fighters if his values, assumptions, and experiences of the world make such a conclusion meaningful. But then she is equally free, for the same reasons, to contest the writer's opinion on the basis of her own values. Names in this theory name mental constructs, just as they do in the empirical perspective, but the difference is that meaning is at least as subjective as it is objective. A fifth response is that naming is a social process dependent on the material interactions of language users who name according to the perspectives they share. As such, naming constitutes a political struggle, a kind of collective bargaining, in which opposing groups vie for the authority to control a discourse. The struggle entails the exercise of power, and the group that prevails in the representation sets the terms of meaning. If Louise believes this view, she recognizes the need to invoke or marshal political support for her position in order to resist and challenge the power of the newspaper account. A sixth response is that naming is part of a language game motivated by desire and need that enables us to create humanly satisfying illusions of coherence. The opposition of terrorist and freedom fighter is a rhetorical fiction, intrinsically mischievous and unstable but used to manipulate debate by appeal to a strategic binary, one term of which is privileged. If Louise believes this view, then she understands that the letter writer's representation may be deconstructed, revealing the manipulative logic that sustains it, in order to subvert a conclusion she finds unsatisfying. Louise knows, however, that her own view is a no less bracketed and tentative judgment because the question is ultimately undecidable by any appeal beyond 
the human need to reach some psychically gratifying, albeit impermanent, closure.

Obviously, some of these accounts have enjoyed greater prestige than others in the discursive common sense of European culture. But all of them provide bases from which to make and appraise the value of discursive statements. If Louise were to engage consciously in a process of comparing them, she might recognize that they offer an array of possibilities in the context of which she can identify, examine, confirm, or reconsider the commitments she brings to the project of naming the Palestinian militants. If she has been unreflectively assuming, for example, that the issue is settled by rational definition, grounded in a priori judgments about the behaviors of Palestinian militants, then she's likely to have been comfortable in the view that the letter writer is simply illogical, failing to understand the definition of terrorist. But if she were to recognize that there are alternative possibilities, then her confidence in her own prejudices might be harder to maintain. If Louise can understand, say, the competing belief that names are decided by a gathering of objective evidence, then she may also be able to appreciate the reasonableness of a more tentative stance about her opinion that the Palestinians are terrorists, reexamining both the writer's evidence and her own. Dissonance in that case might provide a cause for reflection. An awareness of competing perspectives may also help Louise to identify the commitments, and the strategies of persuasion, that others might bring to the debate. Is the letter writer implying that his meaning has a metaphysical claim to truth? Louise might have little patience with an appeal she perceives to be based on fundamentalist conviction. And if the writer truly believes the militants have been named by God, he is unlikely to have much tolerance for the error, perhaps even the sin, of believing they are other than what God has said they are. Or is the writer's opinion grounded in personal experience of Palestinians and knowledge of their historical grievances? If he believes that meanings derive from subjective as much as objective responses to the world, then discussion and subsequent new learning may be possible. Louise's disgust at the violence and cruelty of the militants' actions may be set against the writer's awareness of Palestinian economic disenfranchisement and social dislocation in the interest of negotiating their two points of view.

The matter is not quite as simple, however, as this mechanical illustration suggests. Stories about the nature of naming do not direct, or even very effectively guide, people's verbal practices. Rather, they inform practice, comment on it, and provide perspectives from which, selfconsciously, to ratify or critique it. Their distinctive statements on the 
theme of naming, understood in the context of the whole anthology, simultaneously make their own persuasive gestures toward believability and offer counterpoint to the gestures of the others. Neither Louise nor the letter writer necessarily professes allegiance to any one of the six perspectives described above. Were Louise to appraise her position, the reason would not be to identify herself as a card-carrying ideologue of some particular stripe but to orient herself among possible options in a way that satisfies her standards of intellectual and ethical inquiry. The rhetorical perspectives represent, as an anthology, a dispersion of conceptual differences, a framework from within which to speculate about the sufficiency of one's beliefs and actions. Being reflective about discursive practice entails evaluating it by reference to all the stories one has encountered about the meaning of meaning, not choosing some preferable option isolated from the dynamic of internal debate and criticism that makes the anthology useful in the first place. On occasions when it matters, as in the case of high-stakes naming, Louise might scrutinize her beliefs and actions, such as her judgment about whether or not Palestinian militants are terrorists, by recalling the implicit conversation of the competing narratives, much as we invoke the stories of our "literary" experience in order to understand the complexities of our life experience. The alternative perspectives do not serve as orthodoxies restrictively governing the activities of language users. The fundamentalist at Church on Sunday morning feels no intellectual inconsistency, let alone remorse, when making a relative judgment at brunch about whether to throw out milk that has been kept past its sale date. Meanwhile, the relativist who finds labeling Palestinians as terrorists to be unreflective, foundationalist thinking might not hesitate to apply a label of her own, like fundamentalist, to the person judged to be so unreflective. Life isn't simple, and neither are stories. The six supposedly different narratives I've proposed as an anthology of Western rhetorical theory, while plausible enough, are themselves collectively a speculative fiction, my story about the variety of those stories.

\section{RHETORICAL PERSPECTIVES: READING}

High-stakes naming is only one arena in which a self-conscious awareness of beliefs about language, or the lack of self-consciousness, can have practical consequences. Another arena is high-stakes reading, where we are routinely required to make judgments about issues of intentionality, the authority or status of a particular text, the ethos of a writer, and the reliability of textual interpretation. Consider the reading of important 
public documents, those afforded broad cultural or institutional significance, like the US Constitution, for example. George listens intently to the televised grilling of a proposed Supreme Court nominee, recognizing that a battle has long raged in the congressional nominating process between those who favor strict construction of the Constitution and those who argue for readings that adapt to changing historical circumstances. The precise theoretical issue is competing opinions about our ability to deduce a writer's intent. One position argues for the possibility of identifying original, and stable, meanings across time and space, presuming that the meanings are lodged in the text itself, accessible to careful scrutiny. Another argues that original intent is mysterious at best, that meaning is always located in the interpretive transactions between readers and texts in specific cultural and historical circumstances. The stakes in this case are just as high as those in high-stakes naming: Should children be allowed to pray in public schools because judges claim to understand the literal intent of the framers' injunction against making laws "prohibiting the free exercise" of religion? Should people be denied the right to own assault rifles because judges claim that a contemporary interpretation of "the right of the people to keep and bear arms" must be modified to reflect the impertinence of an antiquated concept of "well regulated militia"? As in the case of contested representations, the view a justice holds about discourse, in this case authorial intent, does not resolve an argument about the right to pray in the classroom or to own an AK-47; rather, it certifies the reasonableness, authority, or power of the position the judge chooses to adopt. The strict construction argument allows us to say with conviction that we do or don't accept prayer in public schools because we "know" what the framers meant. The interpretation argument allows us to say that we do or don't accept it because we "know" with equivalent conviction that the constitution is a living document that must be read in the context of contemporary values and issues. In short, beliefs about what writers, texts, and readers can or cannot do inspire opposing frames of mind from within which the arguments for or against school prayer are pursued and evaluated.

Another powerful contemporary example of discursive beliefs driving disputes about the authority of texts is the argument concerning the Bible as a sacred book whose statements command assent even when they pertain to the natural or social, not just the spiritual, world. The discursive question in the case of a sacred book, unlike that of the US Constitution, is not just the accessibility of authorial intent but, more important, the ethos of the author, the status of the text as the revealed 
Word of God, hence incapable of error or misrepresentation. For some believers, the truths of the Bible are presented literally in direct statement; for others, they derive from interpretive effort. In either case, God and his human agents are the writers; their intentions are pure, if not necessarily clear, and the text has a special power to enable communication between the worlds of the divine and the human. For those who believe in the literal meanings of the Bible, even such technical questions as the age of the earth and the origins of human beings are settled beyond any capacity to reopen them or improve upon their answers through alternative discourses such as geology or evolutionary biology. Even for those who assert the responsibility of readers to interpret the sacred book, and who acknowledge a difference between metaphorical and empirical statement, the theological, or social, or ethical meanings available in the Bible are, in principle, discernible and have the force of moral imperatives, once discerned, whether or not they have efficacy in scientific or other discourses. Meanwhile, there are other possible discursive ideologies from within which to view a text like the Bible. The secular reader may admire and value the Bible as literature without investing it with supernatural authority, or may acknowledge its historical interest and seek to match its stories to archeological or anthropological facts, or may criticize it as mere fable and point out its damaging contributions to ignorance or intolerance. In each instance, the disposition to be religious or not is abetted by alternative discursive beliefs.

Let me continue to clarify the relationship I have in mind between beliefs about words and our other beliefs, as well as our thoughts and actions. It isn't a person's view about the ethos of the Bible that leads to a decision about the truth of faith; rather, it is a commitment to belief or disbelief that conditions someone's understanding of the authority of a religious text. In the same way, it isn't a view of authorial intent that leads to someone's opinion about the meaning of the first or second amendment; rather, the commitment to a particular reading is abetted by an assumption regarding the accessibility of the Constitution's meanings. I'm not arguing that one's views about discourse cause other states of belief or dispositions to act. Instead, I'm arguing that those views play a variety of influential roles within still larger states of belief, affect the ways in which beliefs lead to actions, and condition our judgments about the views and actions of others. Whether we are talking about Louise's awareness of the alternative historical theories of representation (naming), or about George's self-consciousness about authorial intent, or about someone else's familiarity with religious and secular views of textual ethos, there are several benefits to the kind of rhetorical 
self-consciousness I'm depicting. One benefit lies in what we can learn about the motivating premises that people bring to their convictions. A second is more reflective awareness of our own beliefs, as they may be contextualized, and perhaps rendered more problematic, by alternative points of view. A third is the enhanced capacity to critique our own views and even change them if and when interrogation shows them to be faulty or insufficient. And a fourth is freedom from the tyranny of unexamined belief, whether one's own or someone else's. If George naively accepts the strict construction argument about the meanings in the Constitution because he is not familiar with alternative points of view, he risks intimidation by the manipulations of an appeal to higher authority-someone's certainty about what the framers meant. If he naively accepts the interpretation argument, he risks falling prey to the manipulations of an appeal to conveniently self-serving relativism, where someone else's conviction about the meaning of a constitutional amendment is supported by a discursive theory that allows, in principle, for as extravagant an imposition of a reader's will upon a text as is necessary to make it come out right. The contention that meanings are infinitely variable is neither more nor less evidently reliable than the contention that meanings are stable across time. Each view belongs to a discursive ideology that can marshal as many historical arguments, and that requires as much analytical scrutiny, as its alternative.

These qualifications notwithstanding, there are some special circumstances where the relationship between a theory of discourse and the advocacy of a position or an action is more or less directly causal. These circumstances arise most commonly in academic debate-the work of educators and scholars-since those who are specially versed in the language arts not surprisingly cultivate enhanced self-consciousness about the practices of language. In academic and educational settings, the conflicts among alternative discursive ideologies play out in the fuss and feathers of scholarly dispute, in classroom lore and method, in pedagogical theory, in curricular decision making, and ultimately in educational public policy. One ready example is the Great Books debate that has raged on and off for the past century, some people arguing that certain texts deserve iconic cultural status and others arguing that no texts offer meanings so intrinsically stable and timeless that they must be read even by people (often students) who fail to find them relevant or satisfying. The underlying issue in this argument is not the problem of how things are named, as in Louise's view of terrorists, or the problem of authorial intent, as in George's thinking about the Constitution, or the question of ethos in the Bible. Instead, it is the possibility of deriving a universal, 
reliable meaning, one to which any and all readers will assent, from the statements of a text. After all, the argument in favor of the existence of Great Books must depend on a degree of confidence that they offer the same knowledge to all who read them, a knowledge about the values and aspirations of the culture they inscribe, a knowledge of the attributes of the hero, a knowledge of right conduct and civic responsibility, a knowledge of good and evil. And the problem we inevitably face in the effort to sustain this confidence is the evidence from our own experience that texts do not so readily resolve to universal meanings.

It is a simple matter to show that even the most pedestrian text can have virtually as many readings as there are available readers. If one were to ask a group of readers, no matter their level of skill or sophistication, to write one sentence apiece representing the essential meaning of the paragraph immediately above, one would find versions of the following sentences, among others: Sometimes a view of discourse leads directly to other beliefs and to actions. Academics have a sophisticated awareness of the problem of reading. Some people believe in Great Books and others don't. Different people don't get the same ideas from a given text. Great Books inscribe the culture. We can't believe in Great Books unless we believe in the possibility of universal meaning. The central problem in the Great Books debate is different from that of debates about naming or authorial intent. I know that this range is possible, and can be readily extended, because I've asked readers to engage in the exercise. So, the question is not, do readers come to different conclusions about the meaning of a text? The question is, what accounts for the differences? And the answer to that question takes us back to the earlier enumeration of rhetorical perspectives. Here are six ways of accounting for the differences: (1) Some readings are wrong headed because sin and the wiles of the devil have clouded readers' judgments. This is hardly a common position in secular discourse today, but it has worked powerfully during those ages when heretics roamed the land and in circumstances when the text at stake enjoyed greater cultural standing than my paragraph can hope to achieve. (2) Some readings are wrong because readers lack the training or discipline or learning or enlightenment to identify the logical paraphrase that exists at the center of this or any text and that accounts for its coherence. (3) Different readings are right or wrong to differing degrees, depending on readers' familiarity with the context of the text, their knowledge of the author, the genre, the historical moment, the texts on which this text is based, and the prose surrounding this particular paragraph. The more reliable the contextual knowledge, the more plausible the reading. (4) Alternative readings are inevitable, but all readings are plausible in 
principle because every reader will see the text from a particular vantage point, reflecting personal experience. (5) Isolated readings inevitably vary, but meanings are ultimately social in nature, so a community of readers, with time to compare their interpretations, can reach group consensus that some readings are, for that group at that moment, more acceptable than others. (6) Texts suffer from an extravagant abundance of meaning, and any particular reading reflects the unruly play of signification, signs modifying other signs to produce psychically (not to say practically) necessary, but also misleading and unstable, fictions of coherence.

The interplay of these theoretical options-the conceptual constellation they define-creates the basis for competing arguments about the Great Books, leading to their acceptance or rejection in schools, to particular kinds of teaching (which either limit or multiply the meanings found in texts), to curricula that include or ignore Great Books, and to public policy that ties Great Books or some other set of texts to cultural enrichment or decay, personal growth or alienation, learning or ignorance, and even economic advantage or decline. Feminist critics, looking at the vast array of masculine and Caucasian authors in the traditional literary canon, have self-consciously posed arguments derived from expressivist, sociological, and deconstructive viewpoints (about which more later) in order to challenge cultural hegemony by representing history itself as a text, as a story of struggle in which white males, the political winners, have written women out of the text, erasing their writings even as they erased their bodies. The feminist critical response has been to "revise" the text, to write women back into history by recovering long unpublished or never published women writers, by arguing for the canonical stature of better-known women writers, by identifying women's ways of writing, and by subverting the canon altogether, exposing its self-justifying fictions of heritage, phallocentric superiority, and aesthetic objectivity. Conservative cultural critics, sometimes consciously invoking Aristotelian metaphysics, have in turn responded to such assaults with arguments about Shakespeare's transcendent genius, conveyed through classic works that speak to people of all times and places, regardless of superficial distinctions of gender, race, and ethnicity. They reaffirm the capacity of Great Books to celebrate and pass along to new generations the fundamental verities of Western civilization. These academic arguments are not merely opinionated stances about what or how to teach, with inarticulate assumptions about language lurking unexamined behind the commitments. They are arguments about language itself, constituting a struggle in which discursive ideologies overtly 
display their competing claims to authority through the expositions of literary, rhetorical, aesthetic, psychological, and educational theory.

\section{SIX STORIES ABOUT DISCOURSE}

In all these instances, then-whenever issues of high-stakes naming, intentionality in texts, the ethos of authors, and the accessibility of textual meaning arise in public settings-an awareness of competing theoretical perspectives on language and discourse can offer not just intellectual interest but practical opportunity for more reflective thinking and acting. So, I want to turn now to a review of six alternative Western rhetorical theories with those advantages, practical as well as intellectual, in mind. But before elaborating the six "stories" about the meaning of meaning that I've sketched here in summary, let me add a few additional stipulations and clarifications, beginning with some terms that will come up repeatedly in the accounts to follow. By the word rhetoric I mean the theory and practice of public discourse, the arts of communication, argument, narrative, and persuasion. Western rhetoric has two historical dimensions, one philosophical and the other technical, to use the terminology of George Kennedy (Kennedy 1999). I will have little to say about the latter cookbook tradition, but disappointed readers may find recipes aplenty, from the classical Rhetorica ad Herennium to the panoply of modern composition textbooks. By discourse I mean what Ludwig Wittgenstein (1968) meant by "language game," a system of conventions governing the game's players (speakers, writers, hearers, readers), together with the objectives, strategies, tactics, motives, moves, and rewards that shape its play. Discourse can refer either to language use in general or to a specific set of conventions, those governing legal discourse, for example, as opposed to medical or scientific discourse. Rhetoric is about discourse. By text I mean a particular language act, a spoken or written statement that has been constructed according to the conventions of a discourse. The history of rhetoric in Europe is notably a history of the definitions of the word. Rhetoric has been defined very restrictively in some theoretical perspectives, the study of "the available means of persuasion," for example, according to Aristotle, who limits its domain exclusively to spoken, natural language in three discoursesthe political assembly, the law court, and the ceremonial occasion. But it has also had all-inclusive definitions, where virtually any form of signifying activity-painting, football, cinema, mathematics, ritual, clothing fashions, structures of kinship, dance-not just natural language activity, is regarded as discursive and therefore rhetorical. My definition will 
encourage a broader range of applications (and therefore of historical writers whose theories I'll regard as rhetorical) than Aristotle would have recognized, including more than linguistic signs, but it will avoid constituting rhetoric as a Theory of Everything to preserve the hope of distinguishing some things from others.

In the chapters to follow, I use the word story in the sense of account more than in the sense of fiction, although I'm pleased to play on the suggestion of fictionality that the word conveys. The six stories, or accounts, that I will read and write (the dialectic is inescapable) cluster around a common theme, which could be expressed as a question: what encourages us to believe that language acts are meaningful? Each story's answer to the question constitutes its elaboration of the theme, its positing of what I will call a "ground of meaningfulness." The stories constitute discursive ideologies, serving to "explain" the nature of language and its uses, its relationships to self and world, announcing the "truths" that permit users to trust the efficacy of discourse. The six stories are titled "Magical Rhetoric," "Ontological Rhetoric," "Objectivist Rhetoric," "Expressivist Rhetoric," "Sociological Rhetoric," and "Deconstructive Rhetoric." Their sequence should not be taken to imply historical progression or intellectual privilege. They simply make up my anthology. In sum, I'll argue that discourse is meaningful in magical rhetoric because of the intrinsic power of utterance; in ontological rhetoric because of the relationship between language and metaphysics; in objectivist rhetoric because of the relationship between language and phenomenal experience; in expressivist rhetoric because of the relationship between language and consciousness or imagination; in sociological rhetoric because of the material intersubjectivity of language users; and in deconstructive rhetoric because of the situatedness of subjects within the intertextuality of verbal statements. Each "ground" serves to distinguish its story about the meaning of meaning from that of the other stories, and each may also be critiqued from any vantage point except its own.

What makes the stories important is the role they play, largely behind the scenes, as discursive ideologies in the discourses that most matter to us as people and citizens: religion, education, public policy, science, law, history, and others. Magical rhetoric informs our sacred books, the Bible, for example, or the Quran. Ontological rhetoric underlies the inerrancy arguments of Christian fundamentalists and also the arguments that Justice Antonin Scalia of the US Supreme Court poses regarding "textualism," his version of the strict construction view of the Constitution. Objectivist rhetoric informs not only scientific and 
technological discourse but also the No Child Left Behind and Common Core legislation that governs our schools and directs so much attention to educational assessment. Discussions of literacy reflect the differences among several rhetorical perspectives, not coincidentally placing different positions at loggerheads: objectivism supports "functional" literacy arguments; ontological rhetoric informs E. D. Hirsch's (1988) "cultural" literacy; expressivist rhetoric underlies "personal growth" arguments; and sociological rhetoric informs the "critical" pedagogy of Paulo Freire (1969) and Jonathan Kozol (1985). Jean Piaget's (2002) views of child development are objectivist, proposing that infants begin as individual beings and grow through education into social beings; Lev Vygotsky's (1962) views are sociological and propose the opposite, that infants begin as social beings and, through education, gradually differentiate as individuals. Historiography since the seventeenth century has been informed by objectivist rhetoric, emphasizing the empirically based reliability of statements about the past, but counterarguments about the interpretative, unstable, narrative nature of history from Nietzsche to Hayden White have proceeded from the perspective that I'm calling deconstructive rhetoric. Ontological rhetoric offer us conservative values like social stability and enduring truth, objectivist rhetoric valorizes progress through technological ingenuity, expressivist rhetoric emphasizes the importance of the individual and of personal liberties, sociological and deconstructive rhetoric-more radical perspectives by American standards-offer possibilities of political critique and social change. In short, the different assumptions and beliefs featured in these stories work together, and also work against each other, to create the fabric of American public discourse. The stories collectively ratify the meaning of meaning for our culture at this historical moment.

Before proceeding, however, it's important to understand the status of these stories. Simply put, they are my readings of a sampling of texts from the Western rhetorical tradition and occasionally other texts (like the Bible or Karl Popper) that some scholars might not choose to classify as rhetorical at all. I will invoke signatures from the past and present in order to name sources from which my readings/writings derive, but I do not contend that my stories are copies of theirs. Aristotle, Coleridge, and Derrida have told their own stories, whatever they may be, and I tell mine having been provoked by theirs. Including six stories, rather than four or nine, in the anthology has been, philosophically speaking, a somewhat arbitrary decision. It isn't important that there are six but only that the six are different. They are, in the ensemble, intended as a dispersion of intellectual oppositions, linked by appeal to their distinct 
ways of developing their shared theme. The advantage of the differential accounts is precisely their artificiality, their suppression of the (no doubt numerous) conceptual overlaps one could identify among Aristotle, Coleridge, and Derrida were one disposed to tell a story about continuities instead. In my story, these figures are different, discontinuous, and-inevitably_simplified, offering alternative maps of a conceptual terrain that otherwise would shift and blur beyond all hope of purposeful use. Can we speak of the six stories (or, for that matter, my story about them) as true or false? The answer, which should already have become clear, is a decisive yes or no, depending on what one believes about stories. Some of the six narratives about the nature of discourse depicted here are going to take themselves more seriously, as it were, than others do, and make claims for themselves that others do not. The answer to a question about truth and falsity is yes if the questioner speaks from within a more "serious" perspective that regards the question as meaningful. For example, if one agrees with the conditions of an ontological (say, an Aristotelian) perspective, it becomes both possible and necessary to decide the truth or falsity of other positions. But it's impossible, and indeed meaningless, to speak of deciding the issue from within a deconstructive perspective, where stories amplify but neither falsify nor displace others. My story about these stories, meanwhile, does not claim a transcendent position outside the constellation of perspectives they depict, a seventh, master perspective kept secret throughout discussion of the other six. My own preferred location (at the moment) within the intertextuality of these stories necessitates conceding that it's impossible to remove oneself to a place outside them all in order to judge their sufficiency. We must speak from somewhere, and any location conditions what we are entitled to claim.

A final caveat: my anthology is necessarily limited in scope to the extent that a project of reading Western rhetoric is plainly not a project of reading Chinese or Arabic or Indonesian rhetoric. Wherever there is language, there is culture, and wherever there is culture, there is rhetoric-practices of discourse. It follows that there are many stories about the meaning of meaning not encompassed within the cultural framework of the West. The qualification is important, not only because it's true but also because in its truth we're obliged to ponder the long history of colonization that Trinh Minh-ha, who will be discussed in chapter 7, attributes to Western philosophical, logical, rhetorical, and linguistic thought. Restricting my focus to European rhetoric, as I propose to do, arguably risks disparaging other cultural traditions by overlooking them, or worse, appropriating them by appeal to an uncritical assumption that 
they all somehow derive from European roots. Acknowledging the diversity of world rhetorics while nonetheless restricting my focus to the West, I hope to respect rather than erase cultural difference. It's problematic, on one hand, to exclude other rhetorics without implying myopia or superiority. But on the other hand, the elaboration of a framework of grounds of meaningfulness, understood to be saturated in the epistemological assumptions of European culture, cannot legitimately incorporate rhetorics of other cultures that aren't similarly saturated, except at cost of alleging the existence of rhetorical universals and creating a totalizing narrative in which some handful—however large—of chosen rhetorics becomes the master representation of World Rhetoric. Numerous scholars, notably George Kennedy (Kennedy 1998), have written about and continue to explore contrastive features of the world's many rhetorics. Some have avoided the trap of totalization, although Kennedy himself, overtly pursuing the hunt for universals, has not. I commend their efforts-Han Fei Tzu's theory of audience in forensic oratory is not less significant than Aristotle's. But I also hear the stern warning of Molefi Asante about intellectual imperialism when he insists upon the distinctively African foundations of nommo, "the generative and productive power of the spoken word," in The Afro-Centric Idea (Asante 1987, 17). He joins Minh-ha in conjuring the specter of the anthropologist whose presumptuous, all-seeing eye-the eye of European objectivism-can recognize "other" rhetorics in no forms beyond those of the West. My stories are local ... as are all stories. 